\title{
Pediatric cataract: challenges and future directions
}

\author{
This article was published in the following Dove Press journal: \\ Clinical Ophthalmology \\ 7 January 2015 \\ Number of times this article has been viewed
}

\section{Anagha Medsinge ${ }^{1,2}$ \\ Ken $\mathrm{K}$ Nischal ${ }^{1,2}$}

'Pediatric Ophthalmology, Strabismus, and Adult Motility, Children's Hospital of Pittsburgh of University of Pittsburgh Medical Center, (UPMC) ${ }^{2}$ University of Pittsburgh School of Medicine, Pittsburgh, PA, USA
Correspondence: Ken K Nischal Pediatric Ophthalmology, Strabismus, and Adult Motility, Children's Hospital of Pittsburgh of University of Pittsburgh Medical Center, (UPMC) 440I Penn Avenue - Suite 5000, Pittsburgh, PA 15224, USA

$\mathrm{Tel}+\mathrm{I} 4126925918$

Fax +I 4126923203

Email nischalkk@upmc.edu

\begin{abstract}
Cataract is a significant cause of visual disability in the pediatric population worldwide and can significantly impact the neurobiological development of a child. Early diagnosis and prompt surgical intervention is critical to prevent irreversible amblyopia. Thorough ocular evaluation, including the onset, duration, and morphology of a cataract, is essential to determine the timing for surgical intervention. Detailed assessment of the general health of the child, preferably in conjunction with a pediatrician, is helpful to rule out any associated systemic condition. Although pediatric cataracts have a diverse etiology, with the majority being idiopathic, genetic counseling and molecular testing should be undertaken with the help of a genetic counselor and/or geneticist in cases of hereditary cataracts. Advancement in surgical techniques and methods of optical rehabilitation has substantially improved the functional and anatomic outcomes of pediatric cataract surgeries in recent years. However, the phenomenon of refractive growth and the process of emmetropization have continued to puzzle pediatric ophthalmologists and highlight the need for future prospective studies. Posterior capsule opacification and secondary glaucoma are still the major postoperative complications necessitating long-term surveillance in children undergoing cataract surgery early in life. Successful management of pediatric cataracts depends on individualized care and experienced teamwork. We reviewed the etiology, preoperative evaluation including biometry, choice of intraocular lens, surgical techniques, and recent developments in the field of childhood cataract.
\end{abstract}

Keywords: children, pediatric cataract, infantile cataract, aphakia, pseudophakia

\section{Introduction}

Pediatric cataract is one of the major causes of preventable childhood blindness, affecting approximately 200,000 children worldwide, with an estimated prevalence ranging from three to six per 10,000 live births. ${ }^{1-3}$ Pediatric cataracts may be congenital if present within the first year of life, developmental if present after infancy, or traumatic. Early diagnosis and treatment are of crucial importance to prevent the development of irreversible stimulus-deprivation amblyopia. The management of pediatric cataract should be customized depending upon the age of onset, laterality, morphology of the cataract, and other associated ocular and systemic comorbidities.

Recent advances in surgical techniques, intraocular lens (IOL) composition and designs, increased understanding about the neurobiology of visual development, and early postoperative use of contact lenses for optical rehabilitation have contributed to improved outcomes after pediatric cataract surgery. Furthermore, early diagnosis can be achieved by genetic counseling and testing in cases of hereditary cataracts. ${ }^{4}$

However, certain issues specific to pediatric eyes, such as increased postoperative inflammation, axial growth after cataract extraction, implant-power calculation, secondary glaucoma, posterior-capsule opacification (PCO), and amblyopia management, 
are still major obstacles to achieving good visual outcomes in childhood cataract surgery. ${ }^{5-9}$

\section{Examination of the child}

The evaluation of a child with a cataract begins with a detailed history including family history; a prenatal history including maternal drug use and febrile illnesses with rash; and birth history, especially birth weight, since low birth weight may be associated with idiopathic bilateral congenital cataracts. ${ }^{10}$ A developmental history should be carefully assessed, and if required, review should be sought to exclude metabolic or systemic related etiologies. A history of the onset of the lenticular opacities, laterality, and progression is also important. Unilateral cataracts are usually isolated, but they are most commonly found to be associated with persistent fetal vasculature (PFV); ${ }^{11}$ also, other ocular abnormalities, such as lenticonus/lentiglobus may be associated.

A detailed ocular examination is carried out either in the office or in the operating room. This should include slit-lamp biomicroscopy to assess the size, location, density of lenticular opacity, capsular changes, such as preexistent posterior capsular defects, and other associated anteriorsegment developmental anomalies. In addition, measurement of intraocular pressures and corneal diameters are performed. Fundus examination in partial cataracts and ultrasound examination in total cataracts may reveal posterior-segment abnormalities that may affect the visual outcome. Ultrasound biomicroscopy can be informative in children with anteriorsegment developmental anomalies and PFV, and also in the assessment of posterior capsular support while considering secondary IOL implantation (Figure 1). ${ }^{12-14}$ In children under 12 months of age, it is sometimes possible to examine them after they have been fed milk.

In preverbal children who are uncooperative for standard visual acuity testing, fixation behavior, fixation preference, and objection to occlusion should be checked. In younger infants with poorly developed fixation, a red reflex test can be performed in a darkened room with a direct ophthalmoscope along with undilated retinoscopy to assess the visual significance of the lens opacity. A central cataract larger than $3 \mathrm{~mm}$ in diameter, unilateral cataract associated with strabismus, and bilateral cataract with nystagmus are considered visually significant. ${ }^{15}$ Asking about the visual interaction of the child at home with the family members, also helps in determining the severity of visual dysfunction.

It is important to check the visual acuity in older cooperative children, if possible with preferential looking cards (Teller acuity card, Keeler, etc), or other vision tests such as "E” charts

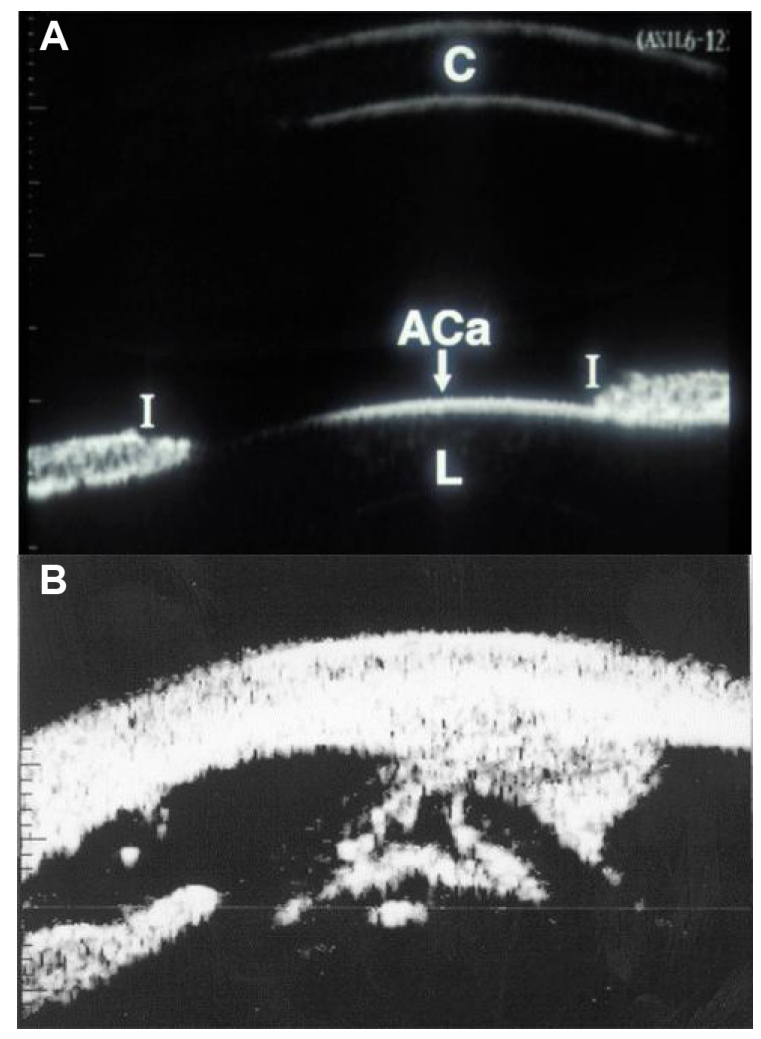

Figure I Ultrasound biomicroscopy images.

Notes: (A) Ultrasound biomicroscopy image depicting anterior segment structures in a normal eye. (B) Ultrasound biomicroscopy showing keratolenticular adhesion (arrow) with cataract in a case of Peter's anomaly. The image demonstrates the utility of anterior segment imaging for pediatric cataract evaluation. Abbreviations: C, cornea; I, Iris; ACa, anterior capsule; L, lens.

or Snellen chart appropriate to the age of the child. In cases of lamellar or posterior subcapsular cataracts, the visual acuity in an examination lane with dim light may appear normal or reasonable, but glare testing where visual acuity drops by two or more lines, will reveal potential difficulty in daylight. The glare test is performed by shining a bright light to the side of each eye as the child attempts to read the vision chart.

\section{Visual evoked potential}

For preverbal, less cooperative, or developmentally delayed children, pattern visual evoked potential (VEP) can be used to assess the effect of the opacity on the visual pathway, thereby indirectly reflecting visual significance of the opacity. ${ }^{16-18}$ Flash VEPs may be useful in complete cataracts to establish the gross integrity of the visual pathways. ${ }^{19}$

\section{Family-album tomography scan}

The parents can be asked to bring the family photograph album if they are unsure about the onset of cataract. Especially when an older child presents with unilateral cataract, inspection of the red reflex in old photographs may give a 
clue as to whether the cataract was present during the critical period of visual development, or not. ${ }^{19}$

\section{Examine the family members}

A dilated slit-lamp examination of the parents and any sibling should be performed, which may reveal previously undiagnosed lenticular changes indicative of an inherited cause for the child's cataract (Figure 2). Female carriers of X-linked conditions associated with males presenting with congenital cataracts may show lenticular changes. Some important examples are punctate lens opacities in a mother of a male child with Lowe syndrome, and Y-sutural opacities in a mother of a male child with Nance-Horan syndrome. ${ }^{16,20,21}$

\section{Morphology of pediatric cataract: specific diagnostic}

A detailed description of the morphology of a pediatric cataract may not only help in the diagnosis of a specific condition but also in planning the management with regard to surgical as well as nonsurgical treatment. Morphologically, pediatric cataracts can be broadly classified into the cataracts involving the entire lens, central cataracts, anterior cataracts, posterior cataracts, punctate lens opacities, coralline cataracts, sutural cataracts, wedge-shaped cataract, and cataracts associated with PFV. ${ }^{11}$ In this review, we want to highlight cataracts with typical morphology specific to certain systemic conditions or syndromes that may be helpful to diagnosis.

Total cataracts can be sporadic or hereditary in nature (Figure 3); they can also be seen in Down's syndrome and congenital rubella syndrome. ${ }^{11}$ Early surgical intervention is mandatory to prevent the development of amblyopia.

Anterior polar cataracts are not pathognomonic of any particular condition, but are commonly seen in patients with

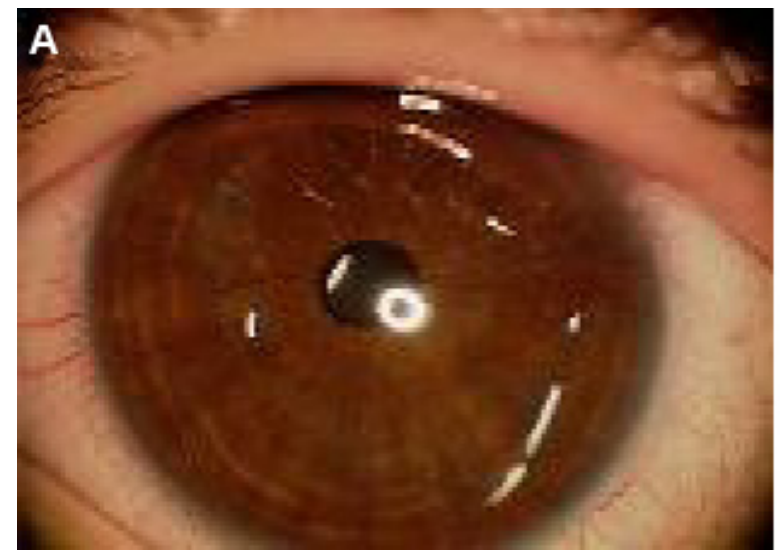

aniridia $^{9}$ (Figure 4A). They can appear as dot-like, plaquelike, or in the form of a pyramid. Pyramidal cataracts are the severe form of anterior capsulolenticular opacities in the form of a pyramid protruding into the anterior chamber, and have also been described in children with retinoblastoma and Ehlers-Danlos syndrome (Figure 4B). 22,23

Anterior subcapsular cataracts are associated with uveitis, trauma, irradiation, and atopic dermatitis. Anterior lenticonus is a bilateral condition seen in Alport syndrome, and rarely in Waardenburg syndrome..$^{24,25}$

Oil-droplet cataracts are the nuclear opacities typically seen in infants with galactosemia (Figure 5). However, other forms of cataract, such as posterior subcapsular or small nuclear and cortical opacification, are also described in galactosemia. ${ }^{26}$ The changes are reversible with early dietary modification.

Sunflower cataract is a type of anterior subcapsular cataract almost only seen in Wilson's disease, an autosomalrecessive condition with a defect in the metabolism of copper leading to accumulation of copper in the liver and basal ganglia. These lenticular opacities are also reversible with treatment with penicillamine. ${ }^{27}$

Posterior subcapsular cataract can be drug-induced (steroids most commonly) or a complication of radiation therapy for ocular and periocular tumors. ${ }^{28,29}$ It has also been reported in systemic conditions, such as Turner's syndrome, Fabry's disease, Bardet-Biedl syndrome, and neurofibromatosis type $2 .^{30-34}$

Membranous cataracts are the disk-like opacities formed after spontaneous resorption of lens material. These are typically seen in Hallermann-Streiff syndrome. ${ }^{35}$ This condition has also been described in children with congenital rubella syndrome, Lowe syndrome, and PFV. ${ }^{36-38}$

Figure 2 Examination of family members.

Notes: (A) Undilated exam that is apparently normal; (B) dilated exam of the same patient revealed punctate cortical opacities. 


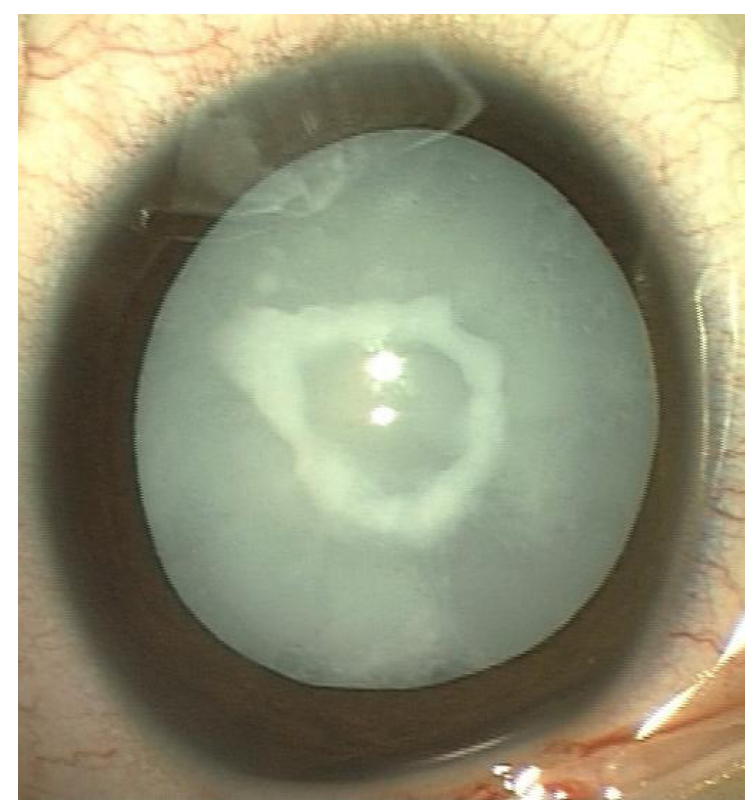

Figure 3 Total cataract with central anterior capsular plaque.

Wedge-shape cataracts are partial lenticular opacities, typically associated with Stickler syndrome in addition to Conradi-Hünermann syndrome, neurofibromatosis type 2, and Fabry's disease. ${ }^{11,39}$

Punctate cortical opacities sparing the nucleus are characteristically seen in carriers of X-linked recessive Lowe syndrome and in children with Down's syndrome. ${ }^{11,21,40}$ Radiating spoke-like cortical punctate opacities are also consistent with Fabry's disease. ${ }^{31}$

Sutural cataracts are visually insignificant opacities along the Y-sutures of the lens. They are often found as an incidental finding on routine examination. They have been described in female carriers of Nance-Horan syndrome, with affected males presenting with dense visually significant cataracts. ${ }^{20}$

\section{Investigations}

Although $60 \%$ of pediatric cataracts are idiopathic, ${ }^{40}$ based on the antenatal history, family history, and the type of cataract, a baseline laboratory workup may be required in some cases. Extensive laboratory investigations are not usually indicated for unilateral cataracts, as most of them are isolated, nonhereditary, and without any systemic associations. ${ }^{40,41}$ However, in any child with a positive maternal antenatal history suggestive of infection or the presence of microcephaly, deafness, cardiac abnormalities, and/or developmental delay should be investigated for varicella, herpes simplex, toxoplasmosis, rubella, and syphilis (TORCHS). ${ }^{42-45}$ Traumatic etiology, particularly of nonaccidental cause, must always be ruled out in any case of unilateral cataract.

Children with bilateral cataracts may be considered in the following way: 1) well infant - rule out galactosemia and TORCHS; 2) well toddler - rule out galactokinase deficiency; 3) jaundiced infant with failure to thrive - rule out galactosemia, urine screening for reducing substances and erythrocyte assays are effective ways to diagnose galactosemia; ${ }^{26,46} 4$ ) unwell infant or child, eg, in a child with coexistent congenital glaucoma, hypotonia, and developmental delay, oculocerebrorenal syndrome (Lowe syndrome) should be ruled out by checking the urine for amino acids. ${ }^{21}$ Specific conditions may need specific testing, eg, serum calcium, phosphorus, and glucose testing should be tailored based on the child's systemic exam. ${ }^{47,48}$
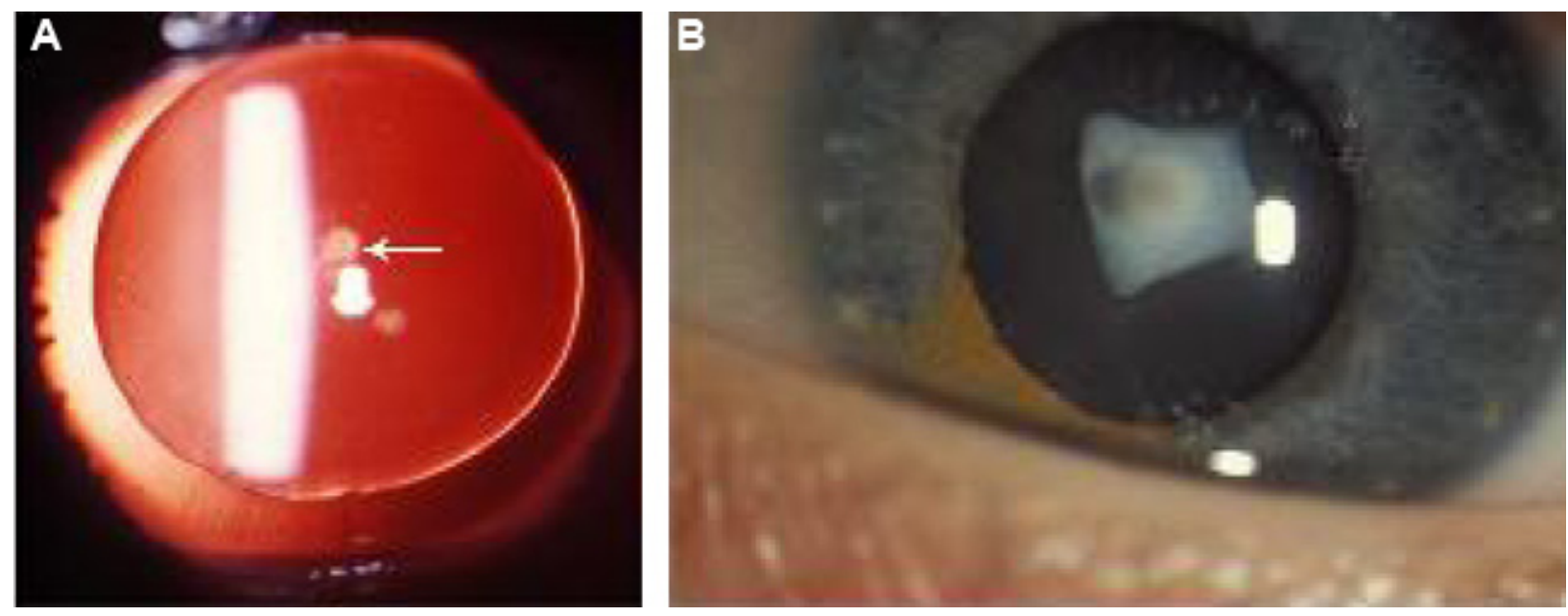

Figure 4 Anterior polar cataract.

Notes: (A) Aniridia with dot-like anterior polar cataract (arrow); (B) pyramidal cataract. 


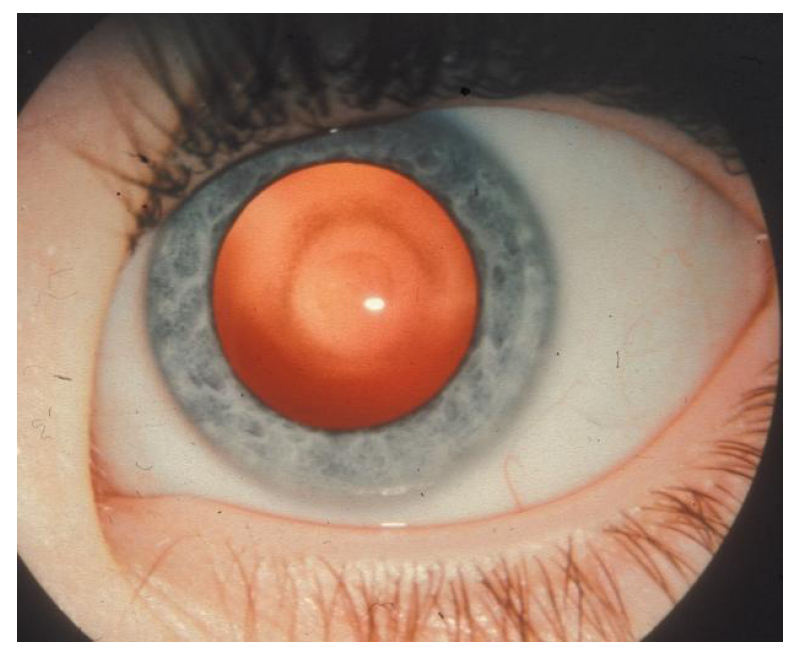

Figure 5 Oil-droplet cataract in galactosemia.

All of these investigations are usually best performed in conjunction with general health assessment of the child by a pediatrician.

\section{Genetic evaluation}

Evaluation by a geneticist is helpful for determining the inheritance pattern and to identify associated syndromes. Genetically based cataracts account for $8 \%-29 \%$ of all congenital cataracts, with the majority being autosomal-dominant in inheritance. ${ }^{49}$ Autosomal-recessive and X-linked patterns have also been isolated. ${ }^{50,51}$ Clinical and genetic heterogeneity is well documented in autosomal-dominant cataracts. ${ }^{52}$ More than 40 different genes and various loci have been identified with congenital cataracts. ${ }^{53}$ Mutations in the genes responsible for the maintenance of lens clarity, such as the crystallin and connexin genes, are the most commonly described in the etiology of nonsyndromic inherited cataracts. ${ }^{49,54}$ Mutations in the genes coding for transcription factors, aquaporin (Maf), beaded filament structural protein, vimentin, and lens intrinsic membrane proteins have also been reported..$^{49,54}$

Mutations in the $\alpha$-crystallin gene tend to cause nuclear, lamellar, zonular, and posterior polar cataracts. In addition to primary cataract, mutation in $C R Y A A$ has been associated with microcornea. Phenotypic variability is commonly observed with mutations in the $\beta$-crystallin genes. ${ }^{55}$ Mutations in the developmental genes, such as PAX6, FOXE3, PITX3, and MAF have also been implicated with cataract as a part of anterior-segment developmental anomalies. ${ }^{53}$ Anterior polar cataracts are commonly seen with $P A X 6$ mutations with or without aniridia, whereas PITX3 mutations predominantly cause posterior polar cataracts..$^{56,57}$
Furthermore, genes responsible for major syndromic cataracts include OCRL (Lowe syndrome), ${ }^{21,58}$ GALK117q (galactosemia), ${ }^{58}$ GLA (Fabry's disease), and NHS (NanceHoran cataract-dental syndrome). ${ }^{59}$

\section{Management Nonsurgical management}

Indication for cataract surgery depends upon how much visual function is affected. The mere presence of a lenticular opacity does not indicate surgical removal. Peripheral lens opacities, punctate opacities with intervening clear zones, and opacities less than $3 \mathrm{~mm}$ in diameter can be observed closely and successfully managed by treating the associated amblyopia by patching and glasses ${ }^{60}$ For example, anterior polar and pyramidal cataracts are not visually significant per se, but can be associated with significant progressive corneal astigmatism, which can lead to decreased visual acuity and amblyopia. ${ }^{11}$ In addition, in small central opacities, a larger area of clear visual axis can be achieved by pharmacological dilatation. ${ }^{62}$ In a recent report, Birch et al found that abnormal visual acuity and contrast sensitivity in young children with partial cataracts was associated with poor long-term visual acuity outcomes. ${ }^{63}$ This suggests that while conservative treatment can be used, it must be done so with caution, and ancillary tests such as glare testing must be utilized to ensure the lens opacity is not visually significant.

\section{Surgical management}

A critical period for visual development has been described in the first 6 weeks of life, during which the vision is subcortically mediated and the infant is relatively resistant to amblyopia ${ }^{64}$ Extraction of unilateral congenital cataracts by 4-6 weeks and bilateral congenital cataracts within the first 6-8 weeks of life can prevent the development of stimulusdeprivation amblyopia, strabismus, and nystagmus. ${ }^{65,66}$ Prompt optical rehabilitation and occlusion therapy can result in good visual acuity with fusion and stereopsis. ${ }^{67}$

\section{A child's eye is unique}

Pediatric eyes are different from adult eyes. They are smaller in size at birth, with changing axial length and corneal curvature over a period of time. The mean axial length of a newborn eye is $16.5 \mathrm{~mm}$. There is rapid growth of eyes in the first 18 months, which increases to $23 \mathrm{~mm}$ by 13 years of age ${ }^{68}$ Similarly, there is a change in the corneal curvature: from 51.2 $\mathrm{D}$ in newborns to 43.5 $\mathrm{D}$ in adults. ${ }^{69,70}$ They have a thin and less rigid sclera, a more elastic capsule, and a risk of severe inflammatory response after surgery. Furthermore, 
a child has a longer life span after cataract removal, with a potential for irreversible visual loss due to amblyopia. Therefore, presurgical evaluation of a growing child's eye is a little complex. Moreover, the process of emmetropization is potentially disrupted.

\section{Preoperative evaluation: biometry}

Optical correction after pediatric cataract surgery may be achieved by aphakic glasses, contact lenses, or primary IOL implantation. Despite the increasing popularity of primary IOL implantation, particularly in young infants, prediction of eye growth over a period of time and choosing an appropriate IOL power to prevent the unexpected refractive change is still a challenge. In a recent survey, approximately $70 \%$ of the American Association of Pediatric Ophthalmology and Strabismus members worldwide preferred to implant an IOL in children. ${ }^{70,71}$ Because of the myopic shift over a period of time, it is essential to predict eye growth and have an accurate biometry in order to choose the appropriate IOL power suited for each child at the time of surgery and well into the future. Accurate measurements of axial length and keratometry in the office setting may be difficult because of poor patient cooperation and poor fixation, and most of the time biometry has to be performed under sedation or general anesthesia in the operating room. Immersion biometry has been shown to be more predictable than the contact method for IOL-power calculation children. ${ }^{72}$

\section{IOL power}

While the general consensus among pediatric cataract surgeons worldwide is partial undercorrection at the time of surgery to balance the postoperative myopic shift, some studies have reported a reduction in axial elongation, and some have reported an increase in axial elongation in young children. ${ }^{73-75}$ Axial elongation has been reported to be more after unilateral cataract extraction in the operated eye than bilateral cataract surgery. ${ }^{5}$ Recent work has documented axial growths in children operated on at 10 years of age, and advised a refractive target of residual mild hyperopia at the time of surgery in older children. ${ }^{76}$ Considering these issues, the choice of IOL power should be individualized based on the child's need and refractive status of the other eye in unilateral cases.

An accurate IOL-calculation formula is required for proper selection of IOL power. SRK II, Holladay 1, Holladay 2, Hoffer Q, SRK/T, and Pediatric IOL Calculator (a computer program) have been used to calculate the desired IOL power in children, with variable results. ${ }^{6,7,77}$ Various factors, including inaccuracies of axial length measurements in the supine position, biometry technique, keratometry values, phenomenon of pseudoaccommodation, variability in IOL position due to capsule fibrosis, and increased corneoscleral elasticity in children, have been suggested to contribute to prediction errors. ${ }^{77-81}$ Additionally, in children younger than 2 years, smaller axial lengths, shallower anterior chambers, and changes in corneal curvature and corneal thickness may lead to higher prediction errors., ${ }^{7,82}$ In the Infant Aphakia Treatment Study (IATS), less than half of the children were within $1.00 \mathrm{D}$ of target refraction, with the greatest prediction errors in eyes with axial lengths of $18 \mathrm{~mm}$ or less. ${ }^{83}$ The recent report of IATS recommended Holladay 1 and SRK/T formulae for infant eyes. ${ }^{84}$ However, at 5 years, they found refractive errors ranging from +5.00 to $-19.00 \mathrm{D}$, and the authors believe that the inability to predict axial elongation in infantile eyes was the primary reason for such a wide range of refractive errors. ${ }^{75,85}$

Absolute prediction errors are common even after secondary IOL implantation, and are reported to range from $0.9 \pm 0.9 \mathrm{D}$ to $2.15 \pm 1.68$ D. ${ }^{86-89}$ Refraction-based formulae by Hug, Khan and Algeed for estimation of secondary posterior-chamber IOL power provide comparable results to those obtained by standard biometry-based formulas, and can be useful in difficult situations when standard biometry cannot be performed or when it is not available in the operating room. ${ }^{86} \mathrm{It}$ is important to note that the Hoffer Q equation relies on an anterior-chamber depth (ACD) value and not on the A-constant. The ACD value is the predicted postoperative ACD. The value given by pharmaceutical companies for each IOL is that for adults. It is larger than that expected for children and especially infants. To use a more accurate ACD value, the author measures the ACD of both eyes and then predicts the ACD, using this value for the Hoffer Q. As a rule of thumb, $1 \mathrm{~mm}$ is added to the preoperative ACD, but this may be modified in unilateral cases, depending on what the ACD is of the unaffected eye. The author uses an empiric rule whereby children under the age of 3 months are left $+8.00 \mathrm{D}, 3$ months to 1 year $+6.00 \mathrm{D}, 1-2$ years $+4.00 \mathrm{D}$, 2-3 years $+3.00 \mathrm{D}, 3-5$ years $+2.00 \mathrm{D}, 5-7$ years $+1.00 \mathrm{D}$, and 7 years and after $+0.5 \mathrm{D}$ until the age of 11 years. These numbers may be modified in unilateral cases, depending upon the refraction of the other eye, so as to cause minimal anisometropia 2 years after surgery.

\section{Type of IOL}

In recent years, acrylic IOLs have gained popularity over polymethyl methacrylate (PMMA) IOLs, which had remained the IOL of choice for many years. ${ }^{71,90,91}$ In children, 
AcrySof IOLs are considered better than PMMA IOLs in terms of greater biocompatibility and smaller incision size with use of foldable design, with late onset and lower rate of PCO formation. Hydrophobic acrylic IOLs are used by $93 \%$ of pediatric cataract surgeons. The one-piece lenses (SA or $\mathrm{SN}$ series) for in-the-bag fixation and three-piece lenses (MA series) for sulcus fixation are preferred. ${ }^{71}$ In children with uveitic cataracts, decreased postoperative inflammation has been reported with the use of heparin-surface-coated PMMA IOLs. ${ }^{92}$ Silicone IOLs are used less frequently, because of an increased rate of capsule contraction. ${ }^{93}$

In special situations, such as in children with dislocated lenses either due to trauma or systemic conditions, such as Marfan's syndrome (Figure 6), transscleral sutured monofocal or multifocal IOLs may be considered for visual rehabilitation. However, limited studies in children have been reported, with a $12 \%-24 \%$ rate of spontaneous dislocation of IOL from suture breakage over a follow-up period of 10 years. This is concerning in the pediatric population because of their longevity. ${ }^{94-96}$ Secondly, transscleral sutured IOL is considered a blind procedure with low accuracy of placement of haptics in the sulcus. ${ }^{97}$

Alternatively, iris-fixated IOLs, such as iris-sutured IOLs and iris-claw IOLs, have been reported with short-term success with complications, including retinal detachment after dislocation, hyphema, synechiae, ectopic pupil, fibrinous uveitis, and vitreous strands in the wound. ${ }^{98,99}$ Few studies exist that report the use of angle-supported anterior-chamber IOLs in older children. ${ }^{100,101}$ A modified capsular tension ring with posterior-chamber IOL implantation is another option in children with partial loss of zonular support. ${ }^{102}$ The indications for multifocal IOLs in children are debatable. Simultaneous distance and near vision without the aid

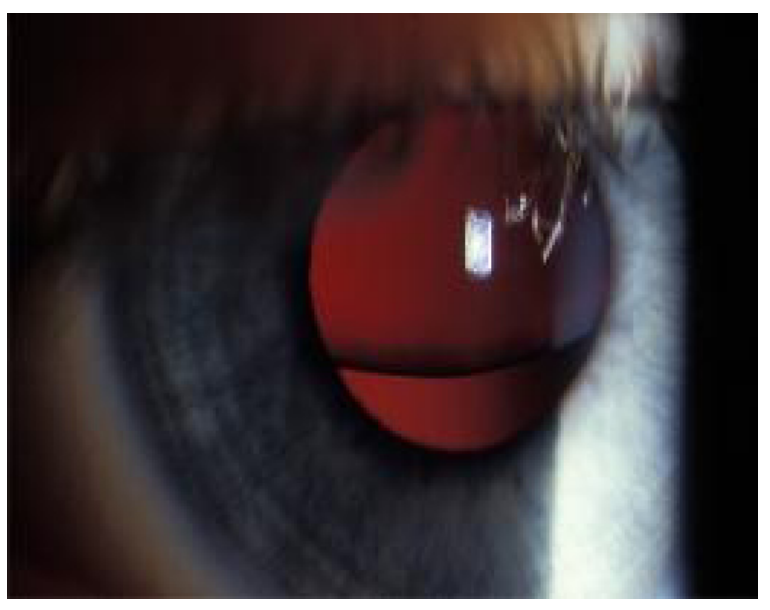

Figure 6 Subluxated lens in a child with Marfan's syndrome. of glasses or contact lenses can be achieved with the use of multifocal IOLs. This is especially important in children, as they lose accommodation once the cataract is removed. Refractive shift during eye growth as well as amblyopia due to loss of contrast sensitivity associated with multifocal IOLs are the main concerns of most pediatric cataract surgeons. ${ }^{71}$ Although limited studies in children have shown improved stereopsis and spectacle independence with the use of multifocal IOLs, studies with long-term follow-up are warranted. ${ }^{103-105}$

\section{Surgical technique Wound}

Cataract surgery in children is challenging, because of increased scleral elasticity, thicker corneas, increased risk of trauma from eye rubbing, less compliance with activity restriction, and most importantly the effect of postoperative astigmatism on amblyopia. While scleral tunnel incision was preferred by most pediatric cataract surgeons because it was thought to induce less postoperative astigmatism, recent studies have shown clinically insignificant difference between the two types of incisions, with spontaneous regression of astigmatism over a period of time. ${ }^{106}$ Superior incisions are commonly performed compared to the temporal approach, probably in view of less risk of injury and postoperative endophthalmitis. As the flattening of the cornea occurs along the incisional meridian, there is a tendency toward withthe-rule astigmatism with the temporal approach in young children. ${ }^{107}$ The temporal approach is desirable in deep-seated eyes and in children with previous or planned filtration surgery superiorly. However, there is no study comparing the astigmatic outcome after pediatric cataract surgery with the superior and temporal approaches. Lensectomy through pars plana approach can also be done if IOL insertion is not intended immediately.

To prevent wound leakage due to the reasons mentioned, suturing of all the wounds, including paracentesis with either a 10-0 or 9-0 Vicryl or nylon suture, is recommended. Absorbable sutures are preferred, in order to avoid a second visit to the clinic or operating room for suture removal. Research has shown that the use of 10-0 Vicryl caused astigmatism, but that this astigmatism dissipated after 6 weeks. ${ }^{108}$

\section{Capsulotomy}

Continuous, smooth, and well-centered anterior capsulotomy is a prerequisite for safe lens implantation. Currently used techniques for pediatric anterior capsulotomies include vitrectorhexis, manual continuous curvilinear capsulorhexis 
(CCC), can-opener, and radio-frequency diathermy. ${ }^{109-112}$ Other devices, such as the plasma blade, diacapsutom, and pulsed-electron avalanche knife, have been suggested to minimize zonular tension and prevent peripheral CCC extension, but have not become popular. ${ }^{113}$ Elasticity and thickness of the anterior capsule in young children makes manual CCC the most difficult technique, with a steep learning curve. It can be performed either with a cystotome or forceps. Manual CCC has been shown to produce the most extensible capsulotomy and the smoothest edge with scanning electron microscopy evaluation in a porcine model. ${ }^{114}$ Although manual CCC has been the gold standard, some surgeons prefer to use the vitrector for very young patients and manual CCC for older children. ${ }^{109}$ The problem with the vitrectorhexis technique is that it is not robust compared to manual CCC. Traditional manual $\mathrm{CCC}$ has a very steep learning curve in children. The two-incision push-pull technique developed by Nischal has been shown to produce consistent-size capsulorhexis openings with minimal risk of extension or tears (Figure 7). ${ }^{115,116}$ Recently, Dick and Schultz described promising results with femtosecond laser-assisted anterior and posterior capsulotomies in four children. ${ }^{117}$ Titiyal et al advocate postage-stamp multiple anterior capsulorhexisotomies to prevent anteriorcapsule phimosis. ${ }^{118}$ For proper centration of the IOL, the anterior capsulotomy should be smaller than the IOL optic. An ideal capsulotomy for an IOL with optic diameter 5.5-6 mm should be $4-5 \mathrm{~mm}$. Smaller capsulotomies may result in severe capsular phimosis, as $15 \%$ shrinkage of the capsular bag diameter occurs over 6 months. ${ }^{119}$

\section{Techniques for cataract extraction}

Surgical techniques for pediatric cataract are constantly evolving to minimize the complication rate. Soft consistency of pediatric cataracts makes phacoemulsification unnecessary. ${ }^{120}$ Lens removal can be conducted through an anterior approach by manual irrigation and aspiration or through the pars plana using a vitrector. In rare cases with membranous cataracts or retrolenticular membranes in PFV, intraocular scissors are required. ${ }^{120}$ An anterior-chamber maintainer used for continuous irrigation prevents the collapse of the anterior chamber during withdrawal of the instruments during the surgery. ${ }^{121}$ It also aids in pupillary dilatation with the use of 1:1,000 epinephrine added to the balanced salt solution. ${ }^{122}$ The use of heparin in the balanced salt solution and intracameral recombinant tissue-plasminogen activator has been shown to reduce the fibrinous reaction and pigment deposits on the IOL. ${ }^{123,124}$ However, the beneficial effect of heparin on early postoperative inflammation has been questioned in a recent randomized controlled trial. ${ }^{125}$ Recently, the use of a transconjunctival 25-gauge vitrectomy system has been gaining popularity for lens removal in pediatric patients. ${ }^{126}$

\section{Posterior-capsule management}

Maintenance of a clear visual axis is critical for a good postoperative visual outcome after pediatric cataract extraction. If the posterior capsule is left intact, $100 \%$ of eyes less than 4 years of age develop significant PCO. ${ }^{127,130}$ The anterior vitreous face acts a scaffold for the proliferation of lens epithelial cells (LECs); therefore, it is essential to combine primary posterior capsulotomy (PPC) with anterior vitrectomy in infants and young children. ${ }^{128,129}$ It can also be considered in older children who are poor candidates for possible neodymium-doped yttrium aluminum garnet (Nd:YAG) laser capsulotomy. PPC can be performed either through a limbal or pars plana approach. The opening for PPC should be smaller than the anterior capsulotomy. Staining of the posterior capsules with trypan blue $0.1 \%$ may facilitate the procedure of PPC. ${ }^{130}$ PPC using the twoincision push-pull technique has been shown to give consistent results without vitreous loss during the procedure. ${ }^{115,116}$ Praveen et al reported triamcinolone-assisted vitrectomy for visualization of the anterior vitreous during pediatric cataract surgery. ${ }^{131}$

Optic capture of the IOL was considered another surgical technique that would obviate the need for anterior vitrectomy and prevent the development of PCO. ${ }^{132}$ However, Vasavada et al believed that anterior vitrectomy was necessary with optic capture even in older children. ${ }^{133}$ Furthermore, it is a difficult technique to perform with singlepiece IOLs without haptic angulation. Posterior vertical capsulectomy with optic entrapment by Grieshaber et al showed promising results in 68 children aged 2 months to 8 years, with clear visual axes for 5-12 years postoperatively. Although this procedure is technically challenging, anterior vitrectomy is seldom required. ${ }^{134}$

Postoperatively, subconjunctival or intracameral steroids are recommended to suppress inflammation in the immediate postoperative period. ${ }^{135,136}$ Intracameral recombinant tissueplasminogen activator has also been shown to reduce the fibrinous reaction and pigment deposits on the IOL after pediatric cataract surgery, though there is a risk of hyphema. ${ }^{124}$ Decrease in the rates of postoperative endophthalmitis in adults has been reported with the intracameral use of antibiotics. However, there is no study showing its effectiveness in the pediatric population. 

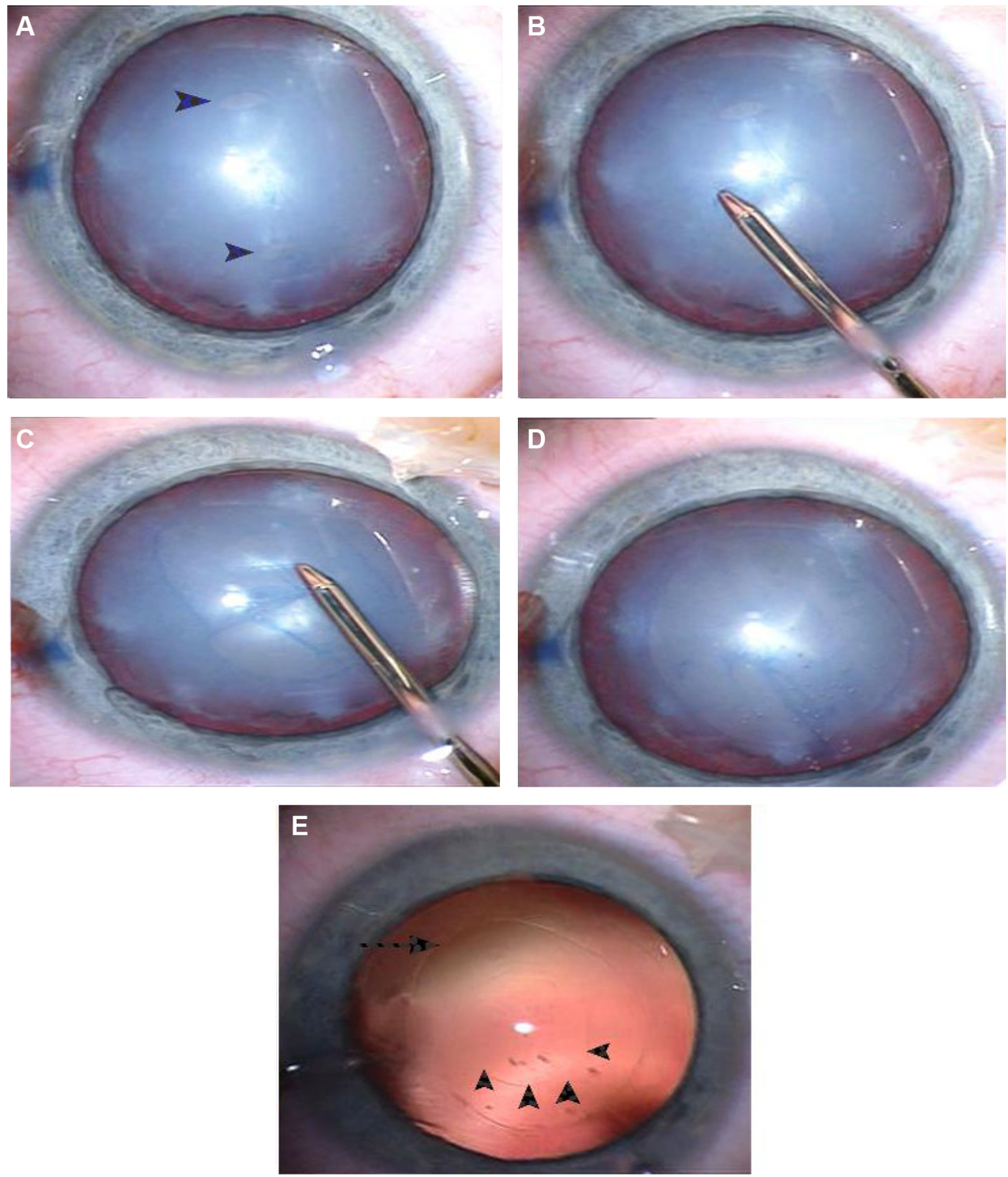

Figure 7 The technique of two-incision push-pull anterior capsulorhexis.

Notes: (A) Two stab incisions are made approximately 4.5-5.0 mm apart in the anterior capsule with a microvitreoretinal blade (arrowheads). (B) Grasping the distal flap of the proximal anterior capsule with capsulorhexis forceps and pushing toward the distal stab incision, making a semicircular rhexis; (C) similarly, the proximal flap of the distal stab incision is then grasped and pulled toward the proximal stab incision. (D) Complete continuous curvilinear capsulorhexis. (E) Anterior (arrow) and posterior two-incision push-pull rhexis (arrowheads) under retroillumination.

\section{Complications}

Postoperative increased inflammatory response in children can lead to fibrinous reactions, pigment deposits on the IOL, decentration of the IOL, and posterior synechiae. Toxic anterior-segment syndrome, which is a well-recognized complication after uneventful adult cataract surgery, has also been reported in children. ${ }^{137}$ Even capsular blockage syndrome has been reported following pediatric cataract surgery. ${ }^{138}$ Secondary glaucoma is the most feared complication of pediatric cataract surgery, and is commonly seen in infants. Studies, including a recent report of the IATS, showed that IOL implantation does not seem to protect from the 
development of secondary glaucoma. ${ }^{85,139}$ However, in a recent meta-analysis, Mataftsi et al found that glaucoma risk after infantile cataract surgery appears to be associated with surgery within the first month of life and additional intraocular surgical procedures, but not with primary IOL implantation. Therefore, the factors influencing the risk for postoperative glaucoma remain an unresolved issue. ${ }^{8}$

Measurement of central corneal thickness in aphakic as well as pseudophakic eyes is essential to diagnose true glaucoma. ${ }^{140}$ Therefore, monitoring for glaucoma is mandatory for any child undergoing cataract surgery early in life. Retinal detachment is a rare late complication of pediatric cataract surgery. ${ }^{141}$ It is not known whether the pars plana approach is associated with increased risk for retinal detachment.

Visual axis opacification remains the most common complication after pediatric cataract surgery. Although PPC, anterior vitrectomy, use of hydrophobic acrylic IOL, or in-the-bag IOL implantation have been effective in preventing or delaying the occurrence of $\mathrm{PCO}$, it is still a major concern in infantile eyes. Severe capsular phimosis can also occlude the visual axis. Nd:YAG laser capsulotomy or surgical membranectomy can be performed to clear the visual axis. Sealed-capsule irrigation using either distilled water or 5-fluorouracil has been shown to be successful in reducing the incidence of visual axis opacification in adult eyes by killing the LECs. ${ }^{142,143}$ This device may help pediatric cataract surgeons to overcome the problem of PCO, but the risk of endothelial cell loss cannot be underestimated. The development of the bag-in-the-lens technique by Tassignon et al shows promise, because by using this lens the LECs are trapped between the anterior and posterior capsules, thus reducing dramatically the rate of PCO. ${ }^{144}$

\section{Vision rehabilitation}

The modalities for visual rehabilitation after pediatric cataract extraction include IOL implantation, aphakic glasses, and contact lenses. Aphakic glasses are an efficient method for visual rehabilitation in children up to 4 years of age. Addition of a bifocal segment is needed in children 4 years of age or older. Contact lenses are usually well tolerated, and the power can be changed until the child is ready for IOL implantation with predictable postoperative refraction. Rigid gas-permeable contact lenses are preferred by the majority of clinicians. ${ }^{145}$ Good visual acuity can be achieved with contact lens fitting within 3 weeks of surgery in unilateral aphakes. ${ }^{146}$ A recent report of the IATS comparing outcomes of contact lens and IOL correction showed no significant difference in median visual acuity between two groups at 5 years, ${ }^{85}$ but showed more complications in the IOL group. No matter what rehabilitation method is used, surveillance is needed.

Unlike adults, visual outcome after a successful cataract surgery in children finally depends on the timely management of amblyopia, especially after unilateral cataract extraction. Generally, patching after pediatric cataract surgery is continued until it is believed that the child is no longer at risk of developing amblyopia. However, there is no consensus about the amount and duration of patching therapy necessary to achieve a good visual result. Extensive occlusion therapy during early infancy may disrupt the development of binocularity. ${ }^{147}$ Compliance with patching has been shown to be associated with good postoperative visual outcomes in unilateral and bilateral cataracts, more so in monocular cataract. ${ }^{148}$ Therefore, educating the parents about the importance of amblyopia therapy postsurgery is crucial.

\section{Future directions}

Despite the better understanding of pathophysiology of visual maturation in children and advancements in surgical technology and instrumentation, childhood cataract remains a challenge to pediatric ophthalmologists.

Prevention of PCO is a major problem faced by the entire pediatric ophthalmology community worldwide. Capsule-irrigating devices customized for pediatric eyes, which will reduce the speed and severity of proliferation of LECs, or future research discovering the drugs antagonizing the effect of factors responsible for PCO are warranted. ${ }^{142,143}$ Recently, the results in an animal model indicated that there was a beneficial effect on postoperative inflammation with dexamethasone-coated IOLs. ${ }^{149}$ It is reasonable to assume that IOLs will be designed that can deliver slow-release molecules to reduce inflammation and obviate the need for topical anti-inflammatory treatment.

Post-operative prediction error is another issue, and there is a need to develop an IOL-calculation formula customized for pediatric eyes to minimize it. Furthermore, future studies are needed to look for the factors, other than secondary glaucoma, affecting postoperative axial growth, so that surgeons will have the ability to predict postoperative refraction and implant an accurately powered IOL in pediatric eyes. There may also be a place for modified implantation techniques and modified IOL designs, such as multicomponent adjustable IOLs (Infinite Vision Optics, Strasbourg, France) to combat refractive surprises. ${ }^{150}$

Appropriate measures, such as immunization programs for rubella and measles and neonatal screening, can reduce 
the incidence in developing countries. Finally, continued genetic studies that will allow clinicians to better understand the natural history and likely outcome of the cataract are required.

\section{Disclosure}

The authors report no conflicts of interest in this work.

\section{References}

1. Foster A, Gilbert C, Rahi J. Epidemiology of cataract in childhood: a global perspective. J Cataract Refract Surg. 1997;23 Suppl 1:601-604.

2. Holmes JM, Leske DA, Burke JP, Hodge DO. Birth prevalence of visually significant infantile cataract in a defined US population. Ophthalmic Epidemiol. 2003;10(2):67-74.

3. Stayte M, Reeves B, Wortham C. Ocular and vision defects in preschool children. Br J Ophthalmol. 1993;77(4):228-232.

4. Lee KA, Park MH, Kim YJ, Chun SH. Isolated congenital hereditary cataract in a dizygotic twin: prenatal ultrasonographic diagnosis. Twin Res Hum Genet. 2013;16(5):994-997.

5. Vasavada AR, Raj SM, Nihalani B. Rate of axial growth after congenital cataract surgery. Am J Ophthalmol. 2004;138(6):915-924.

6. Jasman AA, Shaharuddin B, Noor RA, Ismail S, Ghani ZA, Embong Z. Prediction error and accuracy of intraocular lens power calculation in pediatric patient comparing SRK II and Pediatric IOL Calculator. BMC Ophthalmol. 2010;10:20.

7. Kekunnaya R, Gupta A, Sachdeva V, Rao HL, Vaddavalli PK, Om Prakash V. Accuracy of intraocular lens power calculation formulae in children less than two years. Am J Ophthalmol. 2012;154(1):13-19.e2.

8. Mataftsi A, Haidich AB, Kokkali S, et al. Postoperative glaucoma following infantile cataract surgery: an individual patient data metaanalysis. JAMA Ophthalmol. 2014;132(9):1059-1067.

9. Lim Z, Rubab S, Chan YH, Levin AV. Management and outcomes of cataract in children: the Toronto experience. J AAPOS. 2012; 6(3):249-254.

10. Haargaard B, Wohlfahrt J, Rosenberg T, Fledelius HC, Melbye M. Risk factors for idiopathic congenital/infantile cataract. Invest Ophthalmol Vis Sci. 2005;46(9):3067-3073.

11. Amaya L, Taylor D, Russell-Eggitt I, Nischal KK, Lengyel D. The morphology and natural history of childhood cataracts. Surv Ophthalmol. 2003;48(2):125-144.

12. El Shakankiri NM, Bayoumi NH, Abdallah AH, El Sahn MM. Role of ultrasound and biomicroscopy in evaluation of anterior segment anatomy in congenital and developmental cataract cases. $J$ Cataract Refract Surg. 2009;35(11):1893-1905.

13. De Silva DJ, Nischal KK, Packard RB. Preoperative assessment of secondary intraocular lens implantation for aphakia: a comparison of 2 techniques. J Cataract Refract Surg. 2005;31(7):1351-1356.

14. Mackeen LD, Nischal KK, Lam WC, Levin AV. High-frequency ultrasonography findings in persistent hyperplastic primary vitreous. J AAPOS. 2000;4(4):217-224.

15. Zetterström C, Lundvall A, Kugelberg M. Cataracts in children. $J$ Cataract Refract Surg. 2005;31(4):824-840.

16. McCulloch DL, Skarf B. Pattern reversal visual evoked potentials following early treatment of unilateral, congenital cataract. Arch Ophthalmol. 1994;112(4):510-518.

17. Lloyd IC, Goss-Sampson M, Jeffrey BG, Kriss A, Russell-Eggitt I, Taylor D. Neonatal cataract: aetiology, pathogenesis and management. Eye (Lond). 1992;6(Pt 2):184-196.

18. Nucci P. Pattern reversal visual evoked potentials following early treatment of unilateral, congenital cataract. Arch Ophthalmol. 1995; 113(4):404-406

19. Taylor D, Wright KW, Amaya L, et al. Should we aggressively treat unilateral congenital cataracts? Br J Ophthalmol. 2001;85(9): $1120-1126$.
20. Ding X, Patel M, Herzlich AA, Sieving PC, Chan CC. Ophthalmic pathology of Nance-Horan syndrome: case report and review of the literature. Ophthalmic Genet. 2009;30(3):127-135.

21. Lavin CW, McKeown CA. The oculocerebrorenal syndrome of Lowe. Int Ophthalmol Clin. 1993;33(2):179-191.

22. Kostick AM, Romanchuck KG, Beebe DC. Anterior pyramidal cataracts in Ehlers-Danlos syndrome. Can J Ophthalmol. 1996;31(3):133-136.

23. Brown GC, Shields JA, Oglesby RB. Anterior polar cataracts associated with bilateral retinoblastoma. Am J Ophthalmol. 1979;87(3):276.

24. Liu Z, Sun CB, Yao K. Anterior internal lenticonus accompanied by congenital nuclear cataract. Chin Med J (Engl). 2011;124(23): 4119-4120.

25. Stevens PR. Anterior lenticonus and the Waardenburg syndrome. $\mathrm{Br} J$ Ophthalmol. 1970;54(9):621-623.

26. Beigi B, O'Keefe M, Bowell R, Naughten E, Badawi N, Lanigan B. Ophthalmic findings in classical galactosaemia - prospective study. Br J Ophthalmol. 1993;77(3):162-164.

27. Ram J, Gupta A. Kayser-Fleischer ring and sunflower cataract in Wilson disease. JAMA Ophthalmol. 2014;132(7):873.

28. Suh SY, Kim JH, Kim SJ, Yu YS. Systemic steroid-induced cataracts in children: long-term changes in morphology and visual acuity. JAAPOS. 2013;17(4):371-373.

29. Hoehn ME, Irshad F, Kerr NC, Wilson MW. Outcomes after cataract extraction in young children with radiation-induced cataracts and retinoblastoma. J AAPOS. 2010;14(3):232-234.

30. Eshagian J, Rafferty NS, Goossens W. Human cataracta complicata. Clinicopathologic correlation. Ophthalmology. 1981;88(2):155-163.

31. Sodi A, Ioannidis AS, Mehta A, Davey C, Beck M, Pitz S. Ocular manifestations of Fabry's disease: data from the Fabry Outcome Survey. Br J Ophthalmol. 2007;91(2):210-214.

32. Schachat AP, Maumenee IH. Bardet-Biedl syndrome and related disorders. Arch Ophthalmol. 1982;100(2):285-288.

33. McLaughlin ME, Pepin SM, Maccollin M, Choopong P, Lessell S. Ocular pathologic findings of neurofibromatosis type 2. Arch Ophthalmol. 2007;125(3):389-394.

34. Eshagian J. Human posterior subcapsular cataracts. Trans Ophthalmol Soc U K. 1982;102 Pt 3:364-368.

35. Falls HF, Schull WJ. Hallermann-Streiff syndrome, a dyscephaly with congenital cataracts and hypotrichosis. Arch Ophthalmol. 1960;63(3): 409-420.

36. Boger WP 3rd, Petersen RA, Robb RM. Spontaneous absorption of the lens in the congenital rubella syndrome. Arch Ophthalmol. 1981;99(3): 433-434.

37. Wegener JK, Sogaard H. Persistent hyperplastic primary vitreous with resorption of the lens. Acta Ophthalmol (Copenh). 1968;46(2): $171-175$.

38. Tripathi RC, Cibis GW, Tripathi BJ. Pathogenesis of cataracts in patients with Lowe's syndrome. Ophthalmology. 1986;93(8):1046-1051.

39. Seery CM, Pruett RC, Liberfarb RM, Cohen BZ. Distinctive cataract in the Stickler syndrome. Am J Ophthalmol. 1990;110(2):143-148.

40. Lim Z, Rubab S, Chan YH, Levin AV. Pediatric cataract: the Toronto experience - etiology. Am J Ophthalmol. 2010;149(6):887-892.

41. Haargaard B, Wohlfahrt J, Fledelius HC, Rosenberg T, Melbye M. A nationwide Danish study of 1027 cases of congenital/infantile cataracts: etiological and clinical classifications. Ophthalmology. 2004; 111(12):2292-2298

42. Raghu H, Subhan S, Jose RJ, Gangopadhyay N, Bhende J, Sharma S. Herpes simplex virus-1-associated congenital cataract. Am J Ophthalmol. 2004;138(2):313-314.

43. Lardennois C, Radi-Bencteux S, Trestard L, Marret S, Grangeot-Keros L, Buffet-Janvresse C. Congenital rubella with bilateral cataract detected at 5 weeks. Acta Paediatr. 2004;93(11):1550.

44. Mahalakshmi B, Therese KL, Shyamala G, Devipriya U, Madhavan HN. Toxoplasma gondii detection by nested polymerase chain reaction in lens aspirate and peripheral blood leukocyte in congenital cataract patients: the first report from a tertiary eye hospital in India. Curr Eye Res. 2007;32(7-8):653-657. 
45. Vijayalakshmi P, Kakkar G, Samprathi A, Banushree R. Ocular manifestations of congenital rubella syndrome in a developing country. Indian J Ophthalmol. 2002;50(4):307-311.

46. Beutler E, Matsumoto F, Kuhl W, et al. Galactokinase deficiency as a cause of cataracts. $N$ Engl J Med. 1973;288(23):1203-1206.

47. Pohjola S. Ocular manifestations of idiopathic hypoparathyroidism. Acta Ophthalmol (Copenh). 1962;40(3):255-265.

48. Merin S, Crawford JS. Hypoglycemia and infantile cataract. Arch Ophthalmol. 1971;86(5):495-498.

49. Hejtmancik JF. Congenital cataracts and their molecular genetics. Semin Cell Dev Biol. 2008;19(2):134-149.

50. Craig JE, Friend KL, Gecz J, et al. A novel locus for X-linked congenital cataract on Xq24. Mol Vis. 2008;14:721-726.

51. Ponnam SP, Ramesha K, Tejwani S, Matalia J, Kannabiran C. A missense mutation in LIM2 causes autosomal recessive congenital cataract. Mol Vis. 2008;14:1204-1208.

52. Ionides A, Francis $\mathrm{P}$, Berry $\mathrm{V}$, et al. Clinical and genetic heterogeneity in autosomal dominant cataract. Br J Ophthalmol. 1999;83(7):802-808.

53. Churchill A, Graw J. Clinical and experimental advances in congenital and paediatric cataracts. Philos Trans $R$ Soc Lond B Biol Sci. 2011;366(1568):1234-1249.

54. Francis PJ, Moore AT. Genetics of childhood cataract. Curr Opin Ophthalmol. 2004;15(1):10-15.

55. Gill D, Klose R, Munier FL, et al. Genetic heterogeneity of the Coppocklike cataract: a mutation in CRYBB2 on chromosome 22q11.2. Invest Ophthalmol Vis Sci. 2000;41(1):159-165.

56. Burdon KP, McKay JD, Wirth MG, et al. The PITX3 gene in posterior polar congenital cataract in Australia. Mol Vis. 2006;12:367-371.

57. He Y, Pan Z, Luo F. A novel PAX6 mutation in Chinese patients with severe congenital aniridia. Curr Eye Res. 2012;37(10):879-883.

58. Yasmeen A, Riazuddin SA, Kaul H, et al. Autosomal recessive congenital cataract in consanguineous Pakistani families is associated with mutations in GALK1. Mol Vis. 2010;16:682-688.

59. Burdon KP, McKay JD, Sale MM, et al. Mutations in a novel gene, NHS, cause the pleiotropic effects of Nance-Horan syndrome, including severe congenital cataract, dental anomalies, and mental retardation. Am J Hum Genet. 2003;73(5):1120-1130.

60. Choi J, Kim JH, Kim SJ, Yu YS. Clinical characteristics, course, and visual prognosis of partial cataracts that seem to be visually insignificant in children. J AAPOS. 2012;16(2):161-167.

61. Bouzas AG. Anterior polar congenital cataract and corneal astigmatism. J Pediatr Ophthalmol Strabismus. 1992;29(4):210-212.

62. Drummond GT, Hinz BJ. Management of monocular cataract with longterm dilation in children. Can J Ophthalmol. 1994;29(5):227-230.

63. Birch EE, Subramanian V, Patel CC, Stager D Jr. Preoperative visual acuity and contrast sensitivity in children with small, partial, or noncentral cataracts. J AAPOS. 2013;17(4):357-362.

64. Elston JS, Timms C. Clinical evidence for the onset of the sensitive period in infancy. Br J Ophthalmol. 1992;76(6):327-328.

65. Birch EE, Stager DR. The critical period for surgical treatment of dense congenital unilateral cataract. Invest Ophthalmol Vis Sci. 1996;37(8): 1532-1538.

66. Birch EE, Cheng C, Stager DR Jr, Weakley DR Jr, Stager DR Sr. The critical period for surgical treatment of dense congenital bilateral cataracts. J AAPOS. 2009;13(1):67-71.

67. Lambert SR, Drack AV. Infantile cataracts. Surv Ophthalmol. 1996; 40(6):427-458.

68. Hussain RN, Shahid F, Woodruff G. Axial length in apparently normal pediatric eyes. Eur J Ophthalmol. 2014;24(1):120-123.

69. Gordon RA, Donzis PB. Refractive development of the human eye. Arch Ophthalmol. 1985;103(6):785-789.

70. Wood IC, Hodi S, Morgan L. Longitudinal change of refractive error in infants during the first year of life. Eye (Lond). 1995;9(Pt 5): $551-557$.

71. Wilson ME, Trivedi RH. Choice of intraocular lens for pediatric cataract surgery: survey of AAPOS members. J Cataract Refract Surg. 2007; 33(9):1666-1668.
72. Trivedi RH, Wilson ME. Prediction error after pediatric cataract surgery with intraocular lens implantation: contact versus immersion A-scan biometry. J Cataract Refract Surg. 2011;37(3):501-505.

73. Fan DS, Rao SK, Yu CB, Wong CY, Lam DS. Changes in refraction and ocular dimensions after cataract surgery and primary intraocular lens implantation in infants. J Cataract Refract Surg. 2006;32(7):1104-1108.

74. Griener ED, Dahan E, Lambert SR. Effect of age at time of cataract surgery on subsequent axial length growth in infant eyes. $J$ Cataract Refract Surg. 1999;25(9):1209-1213.

75. Lambert SR, Lynn MJ, DuBois LG, et al. Axial elongation following cataract surgery during the first year of life in the Infant Aphakia Treatment Study. Invest Ophthalmol Vis Sci. 2012;53(12):7539-7545.

76. Trivedi RH, Wilson ME, Bandyopadhyay D. Refractive shift in pseudophakic eyes during the second decade of life. J Cataract Refract Surg. 2012;38(1):102-107.

77. Moore DB, Ben Zion I, Neely DE, et al. Accuracy of biometry in pediatric cataract extraction with primary intraocular lens implantation. J Cataract Refract Surg. 2008;34(11):1940-1947.

78. Mezer E, Rootman DS, Abdolell M, Levin AV. Early postoperative refractive outcomes of pediatric intraocular lens implantation. J Cataract Refract Surg. 2004;30(3):603-610.

79. Neely DE, Plager DA, Borger SM, Golub RL. Accuracy of intraocular lens calculations in infants and children undergoing cataract surgery. J AAPOS. 2005;9(2):160-165.

80. Nihalani BR, VanderVeen DK. Comparison of intraocular lens power calculation formulae in pediatric eyes. Ophthalmology. 2010;117(8): 1493-1499.

81. Nischal KK, Solebo L, Russell-Eggitt I. Paediatric IOL implantation and postoperative refractive state: what role do study methodology and surgical technique play? Br J Ophthalmol. 2010;94(5):529-531.

82. Nihalani BR, Vanderveen DK. Accuracy of intraocular lens power calculation formulae in children less than two years. Am JOphthalmol. 2012;154(4):759-760.

83. VanderVeen DK, Nizam A, Lynn MJ, et al. Predictability of intraocular lens calculation and early refractive status: the Infant Aphakia Treatment Study. Arch Ophthalmol. 2012;130(3):293-299.

84. Vanderveen DK, Trivedi RH, Nizam A, Lynn MJ, Lambert SR. Predictability of intraocular lens power calculation formulae in infantile eyes with unilateral congenital cataract: results from the Infant Aphakia Treatment Study. Am J Ophthalmol. 2013;156(6):1252-1260.e2.

85. Lambert SR, Lynn MJ, Hartmann EE, et al. Comparison of contact lens and intraocular lens correction of monocular aphakia during infancy: a randomized clinical trial of HOTV optotype acuity at age 4.5 years and clinical findings at age 5 years. JAMA Ophthalmol. 2014;132(6):676-682.

86. Abdel-Hafez G, Trivedi RH, Wilson ME, Bandyopadhyay D. Comparison of aphakic refraction formulas for secondary in-the-bag intraocular lens power estimation in children. J AAPOS. 2011;15(5): 32-434.

87. Moore DB, Ben Zion I, Neely DE, Roberts GJ, Sprunger DT, Plager DA. Refractive outcomes with secondary intraocular lens implantation in children. J AAPOS. 2009;13(6):551-554.

88. Nihalani BR, Vanderveen DK. Secondary intraocular lens implantation after pediatric aphakia. $J$ AAPOS. 2011;15(5):435-440.

89. Shenoy BH, Mittal V, Gupta A, Sachdeva V, Kekunnaya R. Refractive outcomes and prediction error following secondary intraocular lens implantation in children: a decade-long analysis. $\mathrm{Br} J$ Ophthalmol. 2013;97(12):1516-1519.

90. Ram J, Jain VK, Agarwal A, Kumar J. Hydrophobic acrylic versus polymethyl methacrylate intraocular lens implantation following cataract surgery in the first year of life. Graefes Arch Clin Exp Ophthalmol. 2014;252(9):1443-1449.

91. Rowe NA, Biswas S, Lloyd IC. Primary IOL implantation in children: a risk analysis of foldable acrylic v PMMA lenses. Br J Ophthalmol. 2004;88(4):481-485.

92. Basti S, Aasuri MK, Reddy MK, et al. Heparin-surface-modified intraocular lenses in pediatric cataract surgery: prospective randomized study. J Cataract Refract Surg. 1999;25(6):782-787. 
93. Pavlovic S, Jacobi FK, Graef M, Jacobi KW. Silicone intraocular lens implantation in children: preliminary results. J Cataract Refract Surg. 2000;26(1):88-95.

94. Buckley EG. Safety of transscleral-sutured intraocular lenses in children. J AAPOS. 2008;12(5):431-439.

95. Asadi R, Kheirkhah A. Long-term results of scleral fixation of posterior chamber intraocular lenses in children. Ophthalmology. 2008; 115(1):67-72.

96. Jacobi PC, Dietlein TS, Jacobi FK. Scleral fixation of secondary foldable multifocal intraocular lens implants in children and young adults Ophthalmology. 2002;109(12):2315-2324.

97. Kamal AM, Hanafy M, Ehsan A, Tomerak RH. Ultrasound biomicroscopy comparison of ab interno and ab externo scleral fixation of posterior chamber intraocular lenses. J Cataract Refract Surg. 2009;35(5):881-884.

98. Sminia ML, Odenthal MT, Wenniger-Prick LJ, Gortzak-Moorstein N, Völker-Dieben HJ. Traumatic pediatric cataract: a decade of follow-up after Artisan aphakia intraocular lens implantation. J AAPOS. 2007;11(6):555-558.

99. Yen KG, Reddy AK, Weikert MP, Song Y, Hamill MB. Iris-fixated posterior chamber intraocular lenses in children. Am J Ophthalmol. 2009;147(1):121-126.

100. Epley KD, Shainberg MJ, Lueder GT, Tychsen L. Pediatric secondary lens implantation in the absence of capsular support. J AAPOS 2001;5(5):301-306.

101. Morrison D, Sternberg P, Donahue S. Anterior chamber intraocular lens (ACIOL) placement after pars plana lensectomy in pediatric Marfan syndrome. J AAPOS. 2005;9(3):240-242.

102. Cionni RJ, Osher RH, Marques DM, Marques FF, Snyder ME, Shapiro S. Modified capsular tension ring for patients with congenital loss of zonular support. J Cataract Refract Surg. 2003;29(9):1668-1673.

103. Cristobal JA, Remon L, Del Buey MA, Montes-Mico R. Multifocal intraocular lenses for unilateral cataract in children. J Cataract Refract Surg. 2010;36(12):2035-2040.

104. Jacobi PC, Dietlein TS, Konen W. Multifocal intraocular lens implantation in pediatric cataract surgery. Ophthalmology. 2001;108(8):1375-1380.

105. Ram J, Agarwal A, Kumar J, Gupta A. Bilateral implantation of multifocal versus monofocal intraocular lens in children above 5 years of age. Graefes Arch Clin Exp Ophthalmol. 2014;252(3):441-447.

106. Bar-Sela SM, Spierer A. Astigmatism outcomes of scleral tunnel and clear corneal incisions for congenital cataract surgery. Eye (Lond). 2006;20(9):1044-1048.

107. Lam HY, Yen KG. Change in astigmatism after temporal clear corneal cataract extraction in the pediatric population. Open Ophthalmol J. 2008;2:43-45.

108. Bar-Sela SM, Spierer O, Spierer A. Suture-related complications after congenital cataract surgery: Vicryl versus Mersilene sutures. J Cataract Refract Surg. 2007;33(2):301-304.

109. Bartholomew LR, Wilson ME Jr, Trivedi RH. Pediatric anterior capsulotomy preferences of cataract surgeons worldwide: comparison of 1993 2001, and 2003 surveys. J Cataract Refract Surg. 2007;33(5):893-900.

110. Gimbel HV, Neuhann T. Development, advantages, and methods of the continuous circular capsulorhexis technique. J Cataract Refract Surg. 1990;16(1):31-37.

111. Wilson ME Jr, Trivedi RH, Bartholomew LR, Pershing S. Comparison of anterior vitrectorhexis and continuous curvilinear capsulorhexis in pediatric cataract and intraocular lens implantation surgery: a 10-year analysis. J AAPOS. 2007;11(5):443-446.

112. Wood MG, Schelonka LP. A porcine model predicts that a can-opener capsulotomy can be done safely in pediatric patients. J AAPOS. 1999 3(6):356-362.

113. Grueterich M, Lackerbauer CA, Kampik A. Performance of the Acri. Smart 46S intraocular lens in pediatric microincision cataract surgery. $J$ Cataract Refract Surg. 2008;34(4):591-595.

114. Trivedi RH, Wilson ME Jr, Bartholomew LR. Extensibility and scanning electron microscopy evaluation of 5 pediatric anterior capsulotomy techniques in a porcine model. J Cataract Refract Surg. 2006; 32(7):1206-1213.
115. Nischal KK. Two-incision push-pull capsulorhexis for pediatric cataract surgery. J Cataract Refract Surg. 2002;28(4):593-595.

116. Hamada S, Low S, Walters BC, Nischal KK. Five-year experience of the 2-incision push-pull technique for anterior and posterior capsulorrhexis in pediatric cataract surgery. Ophthalmology. 2006;113(8): 1309-1314

117. Dick HB, Schultz T. Femtosecond laser-assisted cataract surgery in infants. J Cataract Refract Surg. 2013;39(5):665-668.

118. Titiyal JS, Sinha R, Sharma N, Vajpayee RB. Postage stamp multiple anterior capsulorhexisotomies in pediatric cataract surgery. $B M C$ Ophthalmol. 2005;5:3.

119. Tehrani M, Dick HB, Krummenauer F, Pfirrmann G, Boyle T, Stoffelns BM. Capsule measuring ring to predict capsular bag diameter and follow its course after foldable intraocular lens implantation. J Cataract Refract Surg. 2003;29(11):2127-2134.

120. Amaya L, Taylor D, Russell I, Nischall K. Phacoaspiration in children. J Cataract Refract Surg. 2001;27(10):1534-1535.

121. Dahan E. Intraocular lens implantation in children. Curr Opin Ophthalmol. 2000;11(1):51-55.

122. Dharmaraj S, Azar N. Controversies of implanting intraocular lenses in infancy. Int Ophthalmol Clin. 2005;45(4):61-81.

123. Bayramlar H, Totan Y, Borazan M. Heparin in the intraocular irrigating solution in pediatric cataract surgery. J Cataract Refract Surg. 2004; 30(10):2163-2169

124. Siatiri H, Beheshtnezhad AH, Asghari H, Siatiri N, Moghimi S, Piri N. Intracameral tissue plasminogen activator to prevent severe fibrinous effusion after congenital cataract surgery. Br J Ophthalmol. 2005; 89(11):1458-1461.

125. Vasavada VA, Praveen MR, Shah SK, Trivedi RH, Vasavada AR. Anti-inflammatory effect of low-molecular-weight heparin in pediatric cataract surgery: a randomized clinical trial. Am J Ophthalmol. 2012; 154(2):252-258.e4

126. Chee KY, Lam GC. Management of congenital cataract in children younger than 1 year using a 25 -gauge vitrectomy system. J Cataract Refract Surg. 2009;35(4):720-724.

127. Stager DR Jr, Weakley DR Jr, Hunter JS. Long-term rates of PCO following small incision foldable acrylic intraocular lens implantation in children. J Pediatr Ophthalmol Strabismus. 2002;39(2):73-76.

128. Jensen AA, Basti S, Greenwald MJ, Mets MB. When may the posterior capsule be preserved in pediatric intraocular lens surgery? Ophthalmology. 2002;109(2):324-327; discussion 328.

129. Kugelberg M, Zetterström C. Pediatric cataract surgery with or without anterior vitrectomy. J Cataract Refract Surg. 2002;28(10):1770-1773.

130. Saini JS, Jain AK, Sukhija J, Gupta P, Saroha V. Anterior and posterior capsulorhexis in pediatric cataract surgery with or without trypan blue dye: randomized prospective clinical study. J Cataract Refract Surg. 2003;29(9):1733-1737.

131. Praveen MR, Shah SK, Vasavada VA, et al. Triamcinolone-assisted vitrectomy in pediatric cataract surgery: intraoperative effectiveness and postoperative outcome. J AAPOS. 2010;14(4):340-344.

132. Gimbel HV, DeBroff BM. Posterior capsulorhexis with optic capture: maintaining a clear visual axis after pediatric cataract surgery. J Cataract Refract Surg. 1994;20(6):658-664.

133. Vasavada AR, Trivedi RH, Singh R. Necessity of vitrectomy when optic capture is performed in children older than 5 years. $J$ Cataract Refract Surg. 2001;27(8):1185-1193.

134. Grieshaber MC, Pienaar A, Stegmann R. Posterior vertical capsulotomy with optic entrapment of the intraocular lens in congenital cataracts - prevention of capsule opacification. J Cataract Refract Surg 2005;31(5):886-894.

135. Cleary CA, Lanigan B, O’Keeffe M. Intracameral triamcinolone acetonide after pediatric cataract surgery. J Cataract Refract Surg. 2010;36(10):1676-1681.

136. Mataftsi A, Dabbagh A, Moore W, Nischal KK. Evaluation of whether intracameral dexamethasone predisposes to glaucoma after pediatric cataract surgery. J Cataract Refract Surg. 2012;38(10): 1719-1723. 
137. Huang Y, Dai Y, Wu X, Lan J, Xie L. Toxic anterior segment syndrome after pediatric cataract surgery. J AAPOS. 2010;14(5):444-446.

138. Medsinge A, Nischal KK. Capsular blockage syndrome in a child: a case report. Eye (Lond). 2013;27(11):1333-1334.

139. Trivedi RH, Wilson ME Jr, Golub RL. Incidence and risk factors for glaucoma after pediatric cataract surgery with and without intraocular lens implantation. J AAPOS. 2006;10(2):117-123.

140. Simsek T, Mutluay AH, Elgin U, Gursel R, Batman A. Glaucoma and increased central corneal thickness in aphakic and pseudophakic patients after congenital cataract surgery. $\mathrm{Br} J$ Ophthalmol. 2006;90(9):1103-1106.

141. Rabiah PK, Du H, Hahn EA. Frequency and predictors of retinal detachment after pediatric cataract surgery without primary intraocular lens implantation. J AAPOS. 2005;9(2):152-159.

142. Milverton EJ. Irrigation of the capsular bag using a sealed-capsule irrigation device and 5-fluorouracil. Eye (Lond). 2009;23(8): 1746-1747.

143. Rekas M, Kluś A, Kosatka M. Sealed-capsule irrigation with distilled deionized water to prevent posterior capsule opacification-prospective, randomized clinical trial. Curr Eye Res. 2013;38(3):363-370.
144. Tassignon MJ, De Veuster I, Godts D, Kosec D, Van den Dooren K, Gobin L. Bag-in-the-lens intraocular lens implantation in the pediatric eye. J Cataract Refract Surg. 2007;33(4):611-617.

145. Baradaran-Rafii A, Shirzadeh E, Eslani M, Akbari M. Optical correction of aphakia in children. $J$ Ophthalmic Vis Res. 2014;9(1):71-82.

146. Chen YC, Hu AC, Rosenbaum A, Spooner S, Weissman BA. Longterm results of early contact lens use in pediatric unilateral aphakia. Eye Contact Lens. 2010;36(1):19-25.

147. Wright KW, Matsumoto E, Edelman PM. Binocular fusion and stereopsis associated with early surgery for monocular congenital cataracts. Arch Ophthalmol. 1992;110(11):1607-1609.

148. Chak M, Wade A, Rahi JS. Long-term visual acuity and its predictors after surgery for congenital cataract: findings of the British Congenital Cataract Study. Invest Ophthalmol Vis Sci. 2006;47(10):4262-4269.

149. Kugelberg M, Shafiei K, van der Ploeg I, Zetterström C. Intraocular lens as a drug delivery system for dexamethasone. Acta Ophthalmol. 2010;88(2):241-244.

150. Portaliou DM, Kymionis GD, Pallikaris IG. Multi-component adjustable intraocular lenses: a new concept in pediatric cataract surgery. J Refract Surg. 2014;30(1):62-66.
Clinical Ophthalmology

\section{Publish your work in this journal}

Clinical Ophthalmology is an international, peer-reviewed journal covering all subspecialties within ophthalmology. Key topics include: Optometry; Visual science; Pharmacology and drug therapy in eye diseases; Basic Sciences; Primary and Secondary eye care; Patient Safety and Quality of Care Improvements. This journal is indexed on

Submit your manuscript here: http://www.dovepress.com/clinical-ophthalmology-journal

\section{Dovepress}

PubMed Central and CAS, and is the official journal of The Society of Clinical Ophthalmology (SCO). The manuscript management system is completely online and includes a very quick and fair peer-review system, which is all easy to use. Visit http://www.dovepress.com/ testimonials.php to read real quotes from published authors. 